\title{
Correlation of mechanical and electrical properties with processing variables in MWCNT reinforced thermoplastic nanocomposites
}

Doagou-Rad, Saeed; Islam, Aminul; Jensen, Jakob Søndergaard

Published in:

Journal of Composite Materials

Link to article, DOI:

$10.1177 / 0021998318768390$

Publication date:

2018

Document Version

Peer reviewed version

Link back to DTU Orbit

Citation (APA):

Doagou-Rad, S., Islam, A., \& Jensen, J. S. (2018). Correlation of mechanical and electrical properties with processing variables in MWCNT reinforced thermoplastic nanocomposites. Journal of Composite Materials, 52(26), 3681-3697. https://doi.org/10.1177/0021998318768390

\section{General rights}

Copyright and moral rights for the publications made accessible in the public portal are retained by the authors and/or other copyright owners and it is a condition of accessing publications that users recognise and abide by the legal requirements associated with these rights.

- Users may download and print one copy of any publication from the public portal for the purpose of private study or research.

- You may not further distribute the material or use it for any profit-making activity or commercial gain

- You may freely distribute the URL identifying the publication in the public portal 


\title{
Correlation of mechanical and electrical properties with processing variables in MWCNT reinforced thermoplastic nanocomposites
}

\author{
Saeed Doagou-Rad ${ }^{\mathrm{a}, \mathrm{b}, *}$, Aminul Islamª, ${ }^{\mathrm{a}, \mathrm{b}}$ Jakob Søndergaard
} Jensen $^{\mathrm{a}}$

${ }^{a}$ Centre of Acoustic Mechanical Microsystems (CAMM), Technical University of Denmark, Building 352, DK-2800 Kgs. Lyngby, Denmark

${ }^{b}$ Department of Mechanical Engineering, Technical University of Denmark, Produktionstorvet, Building 427A, DK-2800 Kgs. Lyngby, Denmark

* Corresponding author. Tel.: +45-4525-4867; fax: +45-4525-4700. E-mail address: $\underline{\text { sadora@ @mek.dtu.dk }}$

\begin{abstract}
The influence of the processing variables and nanotube content on the mechanical and electrical properties of Polyamide 6,6-based nanocomposites reinforced with Multi-Walled Carbon Nanotubes (MWCNTs) is investigated. Results show that variation in the processing variables such as compounding method, injection melt temperature, injection speed, mold temperature, and holding pressure varies the properties significantly. In fact, composites containing similar contents of the nanofillers show variations in mechanical properties up to $30.0 \%$ and in the electrical properties up to three orders of magnitude. Different processing parameters required for achieving optimal mechanical and electrical performances were also found. Correlation between processing parameters and microstructure within the nanocomposites was also studied. Results show that variation of the processing parameters defines the existence or absence of a nanotube network in the nanocomposite structure. Experimental and micromechanical modeling results show that less control over the nanocomposite morphology and nanotube alignment is achievable in higher nanofiller contents. The underlying mechanisms responsible for the modulation in the properties are also discussed using scanning and transmission electron microscopy, rheological and crystallization investigations. The research provides a recipe to manufacture the tailored nanocomposite with the specified properties for various industrial applications.
\end{abstract}


Keywords: Composites; Injection moulding; Carbon nanotubes; micromechanics; Rheology; Crystallization.

\section{Introduction}

Recent advancements in the realm of science and technology have created new possibilities and opportunities for different industrial applications. Among these novel possibilities, composites reinforced with Carbon Nano Tubes (CNTs) are being considered as viable alternatives to many conventional materials in various industrial applications ${ }^{1-3}$. One of the main reasons for the considerable attention to these nano fillers is that their incorporation in the metallic or polymeric matrix can lead to multifunctional materials. In case of carbon nanotubes, a concurrent enhancement of mechanical and electrical properties is usually pursued. Electrically conductive composites reinforced with MWCNTs can specifically be attractive in many different sensors or damage monitoring applications. In contrast to conventional composites, for which incorporation of fillers usually results in undesirable changes in other properties, the introduction of novel mechanisms by these nanofillers can result into new combination of features, not available elsewhere. In spite of these incredible features, their stable tailored manufacturing as the prerequisite to their effective deployment is still challenging. Furthermore, it is noteworthy to mention that while these nanofillers have not been considered as economically suitable for mass production or larger components, most of the conducted studies on these nanostructured materials has been limited to laboratories. In fact, just a few papers have focused on the behavior of the CNT reinforced nanocomposites produced using industrially viable techniques ${ }^{4-9}$. Therefore, the nature of the correlation between the mechanical and electrical properties in industrially mass produced components as a function of their processing conditions has yet to be investigated and understood ${ }^{10}$.

Polyamide or Nylon 6,6 (PA 6,6) as one of the major engineering polymers is the oldest, cheapest, and the most consumed member of the group of polyamides. PA 6,6 is made by copolymerization of hexamethylene diamine $\left(\mathrm{C}_{6}\right.$ diamine $)$ and adipic acid $\left(\mathrm{C}_{6}\right.$ diacid $)$, i.e. the two segments of the polymer are composed of a monomer having 6 carbons, resulting into the 6,6 classification. In fact, PA 6,6 and PA6,6 based composites because of their advantageous properties are replacing metal components in different industries ${ }^{11}$.

Injection moulding of components from thermoplastic polymers is one of the most preferable and established industrial production processes. However, the involved parameters in this process can radically influence the properties of polymeric composites. The properties of the nanocomposites are effectively influenced by the distribution, dispersion, alignment and the interfacial properties of MWCNTs in the polymer system. Thus, parameters such as injection speed, injection pressure, melting temperature, and mould temperature vary the properties of the nanocomposites drastically ${ }^{5,12,13}$. So far, the 
performed research in this area have shown a general agreement on the enhancing influence of decreasing injection velocity and increasing melt temperature on the electrical conductivities ${ }^{5,14-18}$. However, different results have been reported for the influence of injection pressure and mould temperature on the electrical properties ${ }^{16}$. In contrast, fewer results exist on the influence of the injection molding variables on the mechanical properties $^{9,14,19}$. Stan et al. discussed about the sensitivity of the mechanical properties to the injection pressure, while no other injection molding variable was found to be influential ${ }^{19}$. Rios et al. also showed the complex dependence of the mechanical properties to the injection molding parameters ${ }^{14}$. In fact, variations in the final arrangements of MWCNTs in the polymer matrix can result into completely different behaviors, which should be controlled and tailored to deliver the desired specifications.

The purpose of this study is to investigate the influence of the manufacturing process parameters on the microstructure, mechanical and electrical properties of PA 6,6-based nanocomposites. The correlation between the properties as the result of applied processing parameters are studied in detail. Different contents of MWCNT reinforced nanocomposite specimens are prepared through different compounding methods. The prepared specimens were characterized using uniaxial tensile and electrical experiments. In order to study the influential mechanisms defining the variation in the properties and correlations between the observed behaviors and microstructures, rheological analyses, differential scanning calorimetry (DSC), scanning electron microscopy (SEM), and Transmission electron microscopy (TEM) were employed. Moreover, a micromechanical modeling was conducted in order to understand the influence of the arrangement on the tubes on properties of the nanocomposites.

\section{Experiments}

\subsection{Materials}

The MWCNTs used in this study are catalytic chemical vapor deposition produced thin MWCNTs (NC $7000^{\mathrm{TM}}$ ) by Nanocyl SA, Belgium, with the average aspect ratio of 67 $\left(d_{\text {ave }}=10.4 \mathrm{~nm}\right)^{4}$. The PA 6,6 based master-batch containing $15.0 \mathrm{wt} \%$ of the aforementioned MWCNTs (according to the supplier Nanocyl SA) was selected in the manufacturing process to acquire the desired contents in the nanocomposites. The selected nanotubes are selected since they are economically viable for mass productions. In addition, Altech PA6,6 (ALBIS Plastic $\mathrm{GmbH}$, Germany) $\left(T_{g}=54.8{ }^{\circ} \mathrm{C}, T_{m}=262.9{ }^{\circ} \mathrm{C}\right.$ ) was selected to mix with the master-batch in the dilution process because of its high melt flow index which facilitate the dispersion of the nano additives in the matrix. 


\subsection{Melt mixing}

Melt mixing is a well-stablished method for nanocomposite production that provides several advantages to other methods such as creating considerably less pollutant residuals, mass production, high speed, and less cost, which makes it the preferred method especially in the industrial scales. This process consists of mixing the molten polymer with the defined amount of nano additives through rotational and shear forces to reach the desirable content.

In order to study the influence of the dilution process on the mechanical properties of the nanocomposites, two main processes were compared. The first dilution method, which we call "direct method", is hand-mixing the master-batch and the neat polymer, followed by the melt mixing in the barrel of the injection unit of the injection molding machine. In this process, the two different pellets are melted and mixed simultaneously under the heat, rotation, and shear force of the hot rotating screw just before injection into the mold. This method is especially favorable in mixing different colorants with polymers. The second method is using a twin-screw extruder before injection molding to mix the two different polymer pellets and preparing the new compounds.

A conical counter rotating twin-screw extruder $\left(H A A K E^{\mathrm{TM}}\right.$ Rheomex CTW, $\Phi=31.8 / 20$ $\mathrm{mm}$ rear/front, $\mathrm{L}=300 \mathrm{~mm}$ ) was selected to perform the melt mixing process. Prior to feeding the materials to the extruder, the neat polymer and master-batch pellets were weighted and hand mixed to the desired contents, namely 3.0 and $6.0 \mathrm{wt}$. \% of MWCNTs. The temperature distribution through the five zones (feed section to die) was kept from 265 to $280{ }^{\circ} \mathrm{C}$, with the average temperature of $275^{\circ} \mathrm{C}$.

\subsection{Injection molding}

Injection molding of the nanocomposite specimens was performed on Ferromatik, Milacron, USA following the instructions of ISO 294-1. The geometry of the cavity of the mold was dog-bone shape which was designed based on ISO 527-2 2012. A series of experiments were conducted using a three level four factor factorial design to investigate the influence of the four considered parameters on the properties of the nanocomposites. The four factors were injection velocity $\left(x_{1}\right)$, melt temperature $\left(x_{2}\right)$, mould temperature $\left(x_{3}\right)$, and holding pressure $\left(x_{4}\right)$ (See Table 1). At each experiment after reaching stability, 35 samples were acquired and stored in vacuum bags. Constant cooling time of $10 \mathrm{~s}$ was applied for all the experiments.

Table 1. Set points of injection molding processes. (“-1", "0", and "1" refer to low, medium, and high levels, respectively).

\begin{tabular}{ccccc}
\hline \multirow{2}{*}{ Levels } & \multicolumn{5}{c}{ Factors } \\
\cline { 2 - 5 } & $X_{1}$ & $X_{2}$ & $X_{3}$ & $X_{4}$ \\
\hline
\end{tabular}




\begin{tabular}{c|cccc}
\hline & $(\mathrm{mm} / \mathrm{s})$ & $\left({ }^{\circ} \mathrm{C}\right)$ & $\left.{ }^{\circ} \mathrm{C}\right)$ & (bar) \\
\hline $\mathbf{- 1}$ & 30 & 270 & 30 & 20 \\
$\mathbf{0}$ & 100 & 280 & 60 & 60 \\
$\mathbf{1}$ & 170 & 290 & 90 & 100 \\
\hline
\end{tabular}

\subsection{Characterization}

In order to characterize the mechanical properties of the injection-molded specimens, uniaxial tensile experiments were conducted according to ISO 527-1 2012. From each series of specimens produced via the defined setting and content, 10 samples were selected randomly, and tested in the dry as molded state.

The electrical conductivity experiments were performed on rectangular specimens $(50 \times$ $10 \times 3.8 \mathrm{~mm}$ ). Electrical resistivity of the inner part was measured using two copper electrodes contacting the two ends of the test specimen under constant pressure using the relevant range ohmmeter (Hioki, Japan). The used set-up is the modified version of the setup depicted in our previous publication ${ }^{20}$. In order to ensure the effective contact between the electrodes and the specimen surfaces, the contacting areas were sanded. Conductive carbon tapes were also placed between the contacts. In addition, a constant pressure (40$50 \mathrm{~N}$ ) was applied from the holding screw. At least 10 random specimens were selected to conduct the experiments for each setting and content.

Furthermore, in order to study the dispersion state and other influential mechanisms in the behavior of the nanocomposites produced via different methods, scanning electron microscopy (SEM) (Quanta FEG 200 ESEM, Thermo Fisher Scientific, USA) was employed on the fractured surfaces of the nanocomposites. In addition, transmission electron microscopy (TEM) (FEI Titan 80-300ST TEM, , Thermo Fisher Scientific, USA) was performed on the ultramicrotomed (Leica Ultracut UCT, Germany) films with the 70 $\mathrm{nm}$ thickness in order to study the orientation and arrangement of the nanotubes within the polymeric system.

Melt rheological properties of the nanocomposites were acquired from experiments conducted in AR2000 rheometer (TA Instruments, USA). In order to prepare the $25 \mathrm{~mm}$ disc-shape samples, granulates of nanocomposites were compression molded between the preheated plates for $6 \mathrm{~min}$. Subsequently, the oscillatory shear measurements were performed in nitrogen atmosphere, using $25 \mathrm{~mm}$ parallel plates with $1.0 \mathrm{~mm}$ gap in between. Each experiment was conducted on the three different samples using strains within the linear viscoelastic range, which had already been defined using strain amplitude sweeps.

In order to characterize the crystallization kinetics of the nanocomposites, investigations on nonisothermal crystallization of the nanocomposites were conducted on a Discovery DSC (TA instruments, USA). A sample of 4-6 mg of the nanocomposites was cut from the 
middle section of the injection molded specimens, and placed in sealed aluminum pans. Differential scanning calorimetry (DSC) experiments were performed under Nitrogen atmosphere in the temperature range of $-90^{\circ} \mathrm{C}$ to $310^{\circ} \mathrm{C}$. Experiments were then performed using different heating and cooling rates, namely 10,30 , and $50{ }^{\circ} \mathrm{C} / \mathrm{min}$. The degree of crystallinity was also determined from the second heating, and the enthalpy of fusion in $100 \%$ crystalline PA 6,6 is considered $196 \mathrm{~J} / \mathrm{g}^{21}$.

\section{Results and discussions}

\subsection{Influence of mixing method}

The dispersion state within polymeric nanocomposites is one of the critical parameters in the behavior of these nanostructured materials. In fact, the nanomaterials need to be dispersed properly to be effective. Therefore, they can deliver the expected benefits to their matrix system. Strong Van der Waals attractive forces in combination with the interfacial forces arising from entanglement among the tubes make reaching to acceptable dispersion states a challenging process. The specific geometry of carbon nanotubes with their high aspect ratios acutely deters acquiring an acceptable dispersion state. In fact, the Van der Waals forces are proportional to the inverse of the radius of particles ${ }^{22}$. Therefore, the small size of the carbon nanotubes magnifies these weak forces significantly. The Van der Waals attraction forces for particles with the average diameters of $10 \mathrm{~nm}-1.0 \mu \mathrm{m}$ are $10^{8}-10^{4}$ times stronger than the gravitational forces. In order to break up the nanotube agglomerates and reach to their effective size, the external stress acting on the agglomerates should exceed the bonding strength of the aggregates. This bonding strength arises from the summation of the counteracting Van der Waals attractive and electrostatic repulsive forces ${ }^{23}$.

In order to compare the influence of compounding method on the behavior and structure of the composites, specimens containing $6.0 \mathrm{wt}$. \% of MWCNTs were prepared. It is well known that as the amount of carbon nanotubes increases in the polymer matrix, acquiring a proper dispersion becomes more challenging. This undesirable phenomenon happens because of several interacting parameters including high interfacial energy of the CNTs, significant increase in the viscosity of the mixture, and decrease in the average distance between the individual nanotubes. In other words, when the content of carbon nanotubes exceeds a certain threshold, poor dispersion states and larger sizes of agglomerations inhibit further increase in the properties. However, based on the parameters such as manufacturing method, polymer and CNTs characteristics, etc. this threshold can vary noticeably ${ }^{2,3}$. Fig. 1 shows a comparison between the properties of the nanocomposites produced through the two described dilution methods. As it is evident from the diagrams, the achieved moduli are notably higher $(\sim 40 \%)$ than the elastic modulus of the neat PA 6,6 (Fig. 1(a)). While the elastic moduli of the nanocomposites produced via the two 
different methods are relatively similar (the difference is less than $4 \%$ ), the elastic modulus of the nanocomposites produced from direct method is slightly more. In contrast, the products of the two mixing methods showed different tensile strengths. In fact, the tensile strength of the nanocomposites produced from the direct method was even less than the strength of neat PA 6,6 (Fig. 1(b)). Poor dispersion state in the nanocomposites produced through the direct method led to presence of critical sites with large stress concentration factors in the structure of the composites. These large agglomerates in the microstructure system produce a non-uniform stress distribution while loading. In other words, the large islands of the not wet carbon nanotubes blocked redistribution of the polymer chains. Therefore, the nanocomposites became significantly stiff and brittle, where elongations at breaks were $50 \%$ of the ones in the nanocomposites processed through the twin screw extruder, and a premature failure in low strains happened. In contrast, in the nanocomposites produced through consecutive melt mixing and injection molding, stress transfer was more uniform. The interfacial areas carried most of the applied load and defined the mechanical behavior. Similar trend of the results has also been reported in ${ }^{24}$.

Moreover, the electrical resistivity of the injection-molded specimens that were processed through twin-screw extruder is nearly one order of magnitude lower than the specimens produced using the direct method. However, a very high standard deviation has been achieved for the electrical conductivity of the nanocomposites, which shows poor distribution of the fillers. In other words, the unstable distribution of the fillers is changing from sample to sample in one production cycle. Furthermore, regardless of the injection molding melting temperature, the average electrical conductivities of the nanocomposites produced via direct method were higher than the products of the twin-screw extruder (Fig. $1(\mathrm{c}))$. 

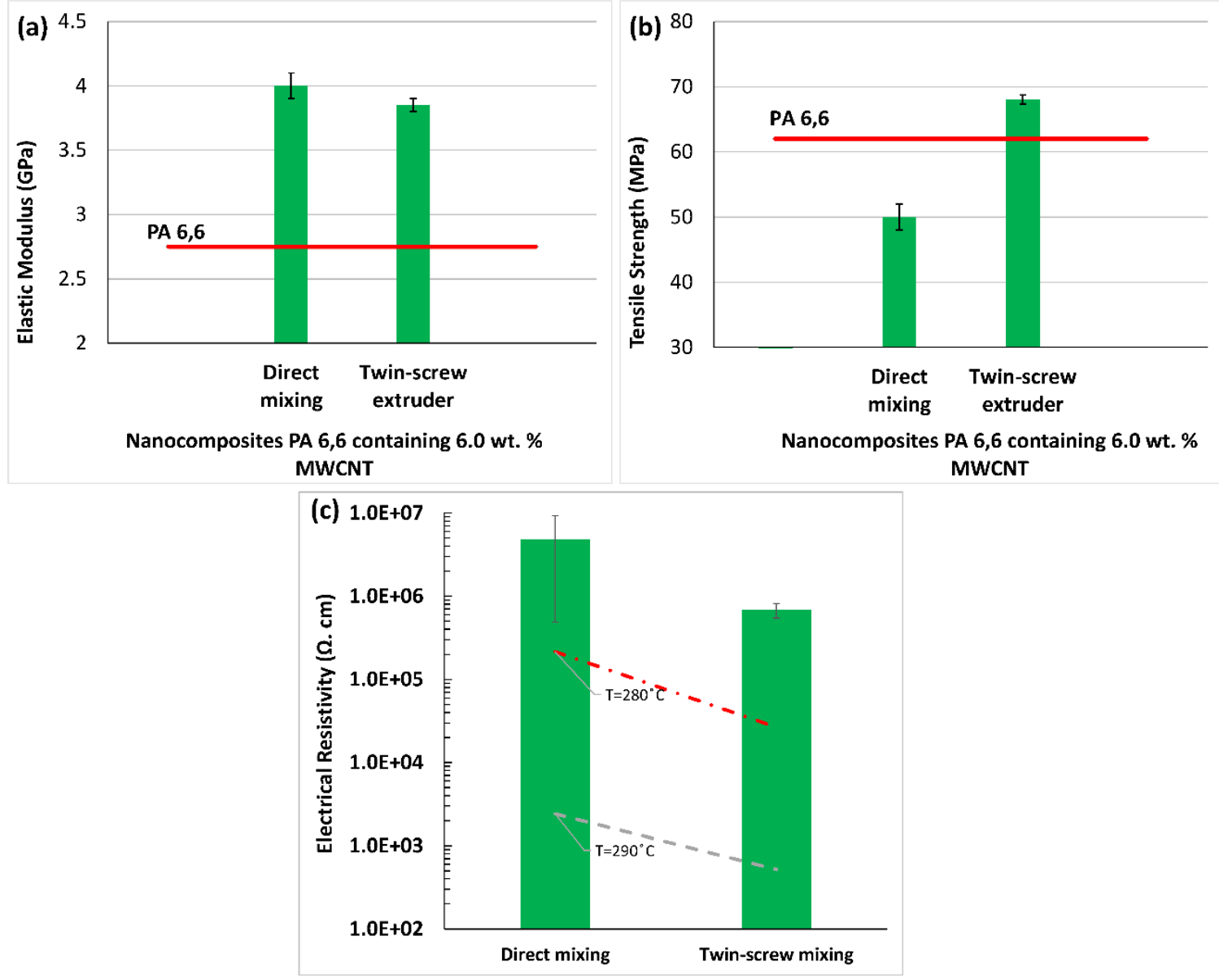

Fig. 1. Comparison between the direct mixing and twin-screw extruder dilution methods: (a) Elastic modulus, (b) tensile strength, and (c) electrical resistivities.

Figs 2 (a) and (b) show the dispersion states of the fracture surfaces of the nanocomposites diluted via the twin-screw extruder and direct methods, respectively. As it can be clearly seen from the SEM images, the dispersion states in the two nanocomposites with same content of MWCNTs $(6.0$ wt. \%) are completely different. In the nanocomposites processed in the twin-screw extruder, carbon nanotubes are fairly well distributed and dispersed. In contrast, in the nanocomposites that are diluted directly in the injection molding machine, separate islands of carbon nanotubes can be noticed. This poor distribution led to the observed lower tensile strengths. However, it is assumed that based on the position of these nanotube islands they might construct a network of the tubes leading to improved electrical behavior.

Figs 2 (c) shows the dispersion stated of the nanocomposites containing 6.0 wt. \% MWCNTs after optimization of compounding process ${ }^{9}$. Although well states of dispersion were acquired in the specimens, very few numbers of agglomerates could still be found (Fig. 2 (d)). It seems that the applied shear forces originating from the consecutive twin- 
screw extruder and injection molding screw were not enough to break down all of the agglomerations in the system in higher contents of fillers. In fact, agglomerations with the maximum diameter $5 \mu \mathrm{m}$ were found in the nanocomposites containing $6.0 \mathrm{wt}$. \% MWCNTs (average number of 3-4 agglomerates in $400 \mu \mathrm{m}^{2}$ ). It is believed that these distributed agglomerates in the matrix act as micro stress concentrations resulting into the deviation from the expected enhancement in the mechanical properties.
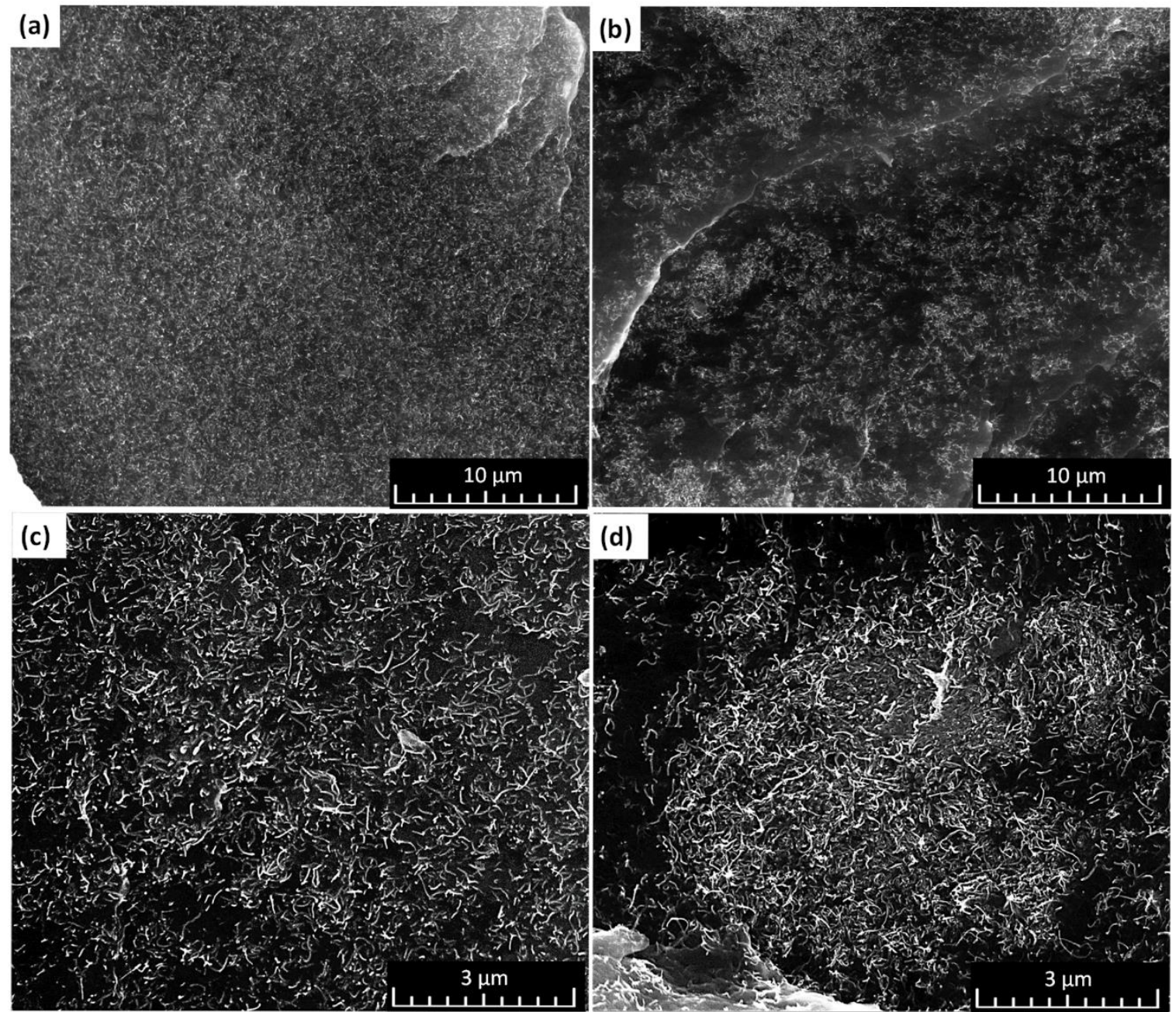

Fig. 2. Dispersion state in $6.0 \mathrm{wt}$ \% MWCNT filled nanocomposites (a) processed in the twin-screw extruder, (b) diluted via the direct method. (c) Dispersed and agglomerate phases in the nanocomposites after mixing optimization.

\subsection{Rheological behavior}

In order to investigate the nanocomposites melt behavior during injection molding process, their rheological properties were studied. Fig 3 (a) shows oscillatory complex 
viscosities of the prepared nanocomposites. As it can be noticed, addition of nanotubes has increased the viscosity of the nanocomposites significantly. In addition, incorporating 6.0 wt. \% MWCNTs additionally increased the viscosities by one order of magnitude more than the specimens containing $3.0 \mathrm{wt}$. \% MWCNTs within the whole frequency range of the experiments. In addition, a linear relationship between the viscosities and the oscillatory frequency is seen. The Newtonian plateau in lower frequencies, which is typical of polymer melts as viscoelastic liquids is also absent. Fig. 3 (b) depicts the storage and loss moduli of neat polymer and the nanocomposites as a function of applied oscillatory frequency. Similar to viscosity, the storage and loss moduli increased significantly with the addition of the nanofillers in the polymer matrix. Furthermore, it should be noted that the storage moduli $\left(G^{\prime}\right)$ are always larger than the measured loss moduli $\left(G^{\prime \prime}\right)$, which is a clear indication of a solid-like behavior $\left(G^{\prime}>G^{\prime \prime}\right)^{25}$. In fact, the viscoelastic response of the materials is usually characterized by the calculation of $\tan \delta=G^{\prime \prime} / G^{\prime}$ as the damping parameter. The introduced damping parameter in the produced MWCNT filled PA 6,6 based nanocomposites was not only always less than one ( $\tan \delta<1$ ), but also decreased additionally by increasing the content of the nanotubes in the polymer matrix, indicating less viscoelastic behavior. It is noteworthy to mention that the damping factor for neat polymer especially in low frequencies is usually above one ( $\left.\left.\tan \delta\right|_{@ 1.0 \mathrm{rad} / \mathrm{s}} ^{\text {PA6, }} \approx 10\right)$, which is significantly higher than of the nanocomposites. This parameter was calculated to be 0.2 ( $\left.\tan \delta\right|_{@ 1.0 \mathrm{rad} / \mathrm{s}} ^{\text {ncomp. } \% \text { MWCNT }} \approx 0.2$ ) in the nanocomposites containing 6.0 wt. \% MWCNTs.
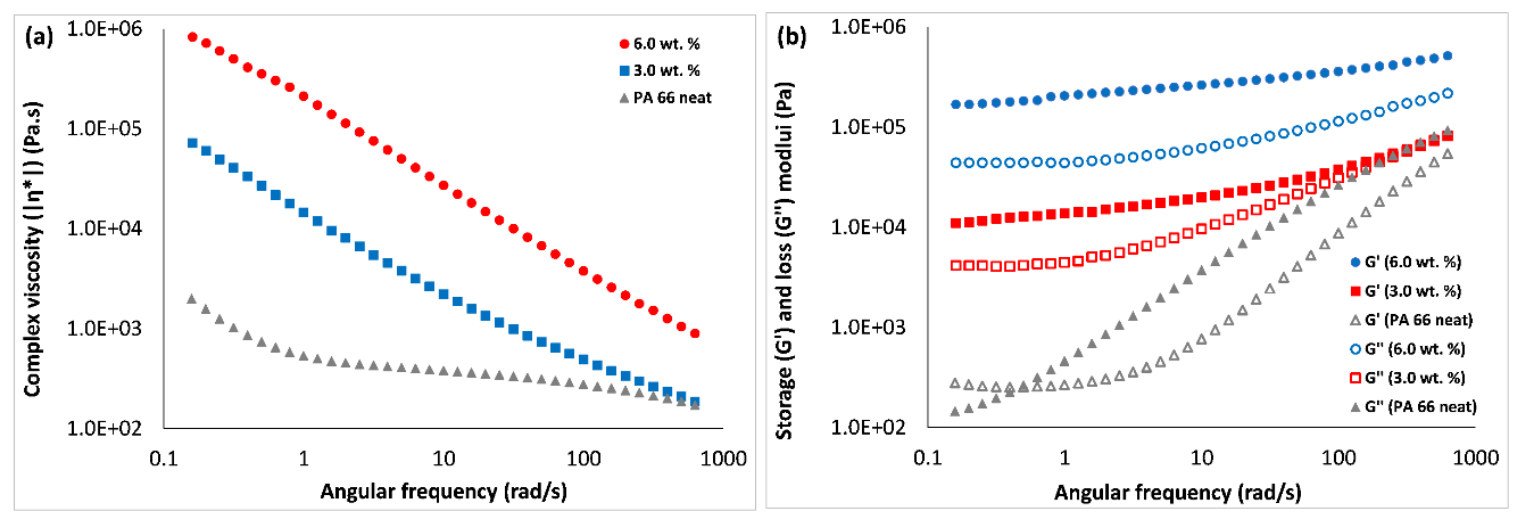

Fig. 3. (a) Complex viscosity, and (b) storage and loss moduli of the neat Nylon 66, and MWCNT filled nanocomposites as a function of angular velocity and nanofiller content.

The shear viscosity behavior of the polymers usually consists of two main regions, namely Newtonian and shear thinning. In contrast to neat polymers, the Newtonian plateau was not observed even for very low frequencies. In fact, the shear thinning is defining the melt behavior, where the viscosity decreases constantly with the increase of frequency. As the content of the nanotubes increases in the polymer system, the interactions between the nanotubes at one level, and between the fibers and the polymer chains at the next level are 
effectively being strengthened. This phenomenon especially in lower frequencies determines the melt behavior. However, its influence decreases in higher frequencies due to shear thinning. As the mean distance between the nanotubes decreases (number of the tubes increases), the influence of the tubes on the melt behavior increases significantly. A constant increase in the nanofiller content eventually leads to the dominant influence of nanotubes fraction over polymer melt. Further above this so called "rheology percolation threshold" $\left(G^{\prime}=G^{\prime \prime}\right)$, the melt properties are mostly controlled by the formed physical network of the nanotubes in the polymer system. This behavior is the characteristic aspect of the nanocomposites in the produced specimens.

Fig. 4 illustrates the relaxation behavior of the nanocomposites as a function of time and temperature after imposing $10 \%$ strain. As the hot melt is injected from the nozzle into the cavity of the mold, it hits the cold wall and solidifies rapidly. Therefore, the final microstructure of the nanocomposites is determined by the residing behavior of the nanocomposite melt in the mold. However, the state of the melt and tubes at the moment of delivery to the mold is also crucial in the final structure of the nanocomposites. Both nanocomposite melts containing 3.0 and $6.0 \mathrm{wt}$. \% MWCNTs responded as pseudo-solid materials. Thus, it can be deduced that the formed supermolecular network restricts longrange movement and free rotation of the polymer chains and nanotubes. Although it might be expected that the observed solid-like behavior decreases the influence of the temperature variation on the rheological behavior; relaxation experiment results showed that the temperature is still a determinant parameter in the final arrangements in the nanocomposites.

Higher stress reduction rates in the lower contents of MWCNTs indicates that the polymer chains and nanotubes rearrange easier and faster. This relative freedom in movement additionally increased at higher melt temperatures due to combination of higher energy and lower viscosities of the system. However, it should be mentioned that a higher energy does not imply free movement, and the slopes are still considerably lower than the neat polymer stress relaxation rates.
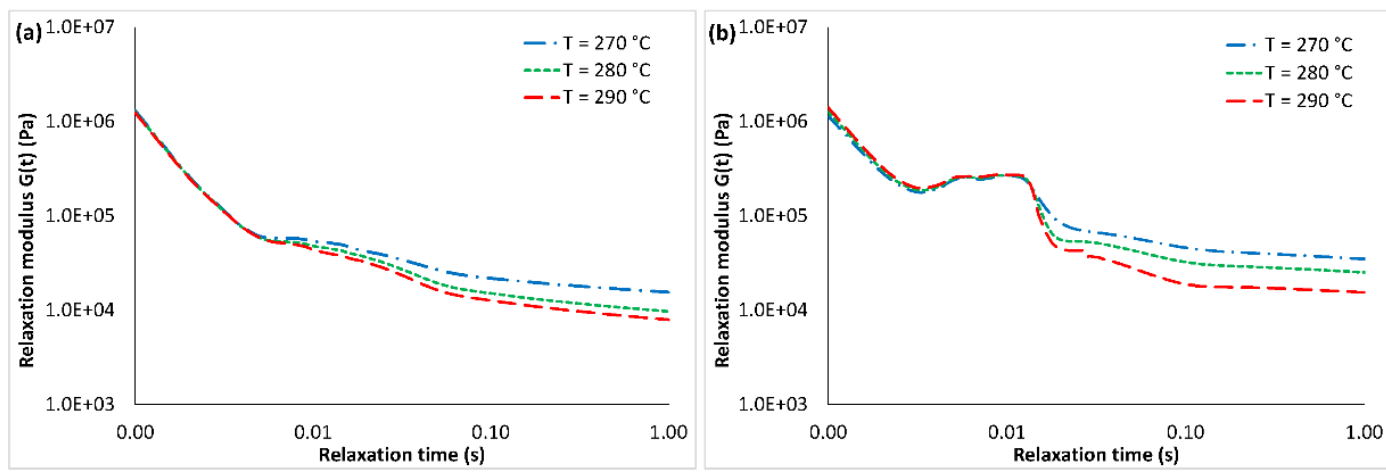

Fig. 4 Relaxation behavior of the nanocomposites containing (a) $3.0 \mathrm{wt}$. \%, and (b) $6.0 \mathrm{wt}$. $\%$ MWCNT as a function of time and temperature. 


\subsection{Crystallization}

Considering the semi-crystalline nature of PA 6,6, one might argue that the variation in the nanocomposites behavior can be attributed to the change in the crystallization properties of the nanocomposites. In order to investigate such influence, crystallization and melting behavior of the nanocomposites were investigated as a function of cooling rates. Figs 5 (a) and (b) show the heating and crystallization behavior of the nanocomposites. In fact, crystallinity in the PA 6,6 and its corresponding composites is a pivotal parameter in both physical and manufacturing aspects of the polymeric products such as variation in the shrinkage of the products or skin-core morphologies. As it can be noticed from the curves, variation in the cooling rates changes the crystallization behavior significantly. Results revealed that increasing the cooling rates shifts the cooling curves toward left. The crystallization peak temperature $\left(T_{C}\right)$ of the nanocomposites containing $6.0 \mathrm{wt}$ \% MWCNTs decreased from $244{ }^{\circ} \mathrm{C}$ to $232{ }^{\circ} \mathrm{C}$ as the cooling rates increased from $10{ }^{\circ} \mathrm{C} / \mathrm{min}$ to $50^{\circ} \mathrm{C} / \mathrm{min}$. This change is due to the thermodynamic irreversibility and time-dependent nature of the crystallization process in semi-crystalline polymers ${ }^{26,27}$. In order to investigate the evolution of this time-dependent process, the relative crystallinity was investigated as a function of time and temperature (Fig. 5 (c) and (d)). The relative degree of crystallinity is defined:

$$
X_{t}=\frac{\int_{T_{\text {Onset }}}^{T_{t}}\left(\frac{d H_{C}}{d T}\right) d t}{\int_{T_{\text {Onset }}}^{T_{\text {Endset }}}\left(\frac{d H_{C}}{d T}\right) d t}
$$

where $H_{C}$ is the crystallization enthalpy, and $T_{\text {Onset }}$ and $T_{\text {Endset }}$ are the beginning and ending temperatures of crystallization, respectively. The half time crystallization $\left(t_{50 \%}\right)$, which is the required time from the start of crystallization at a constant cooling rate to reach the relative degree of crystallinity of $50 \%\left(X_{t}=50 \%\right)$ is one of the efficient tools to investigate this process. As it can be seen from the diagrams, $t_{50 \%}$ decreased noticeably by increasing the cooling rates. Since the process of crystallization for higher cooling rates happens much faster, one can expect different levels of crystallization in the products. 

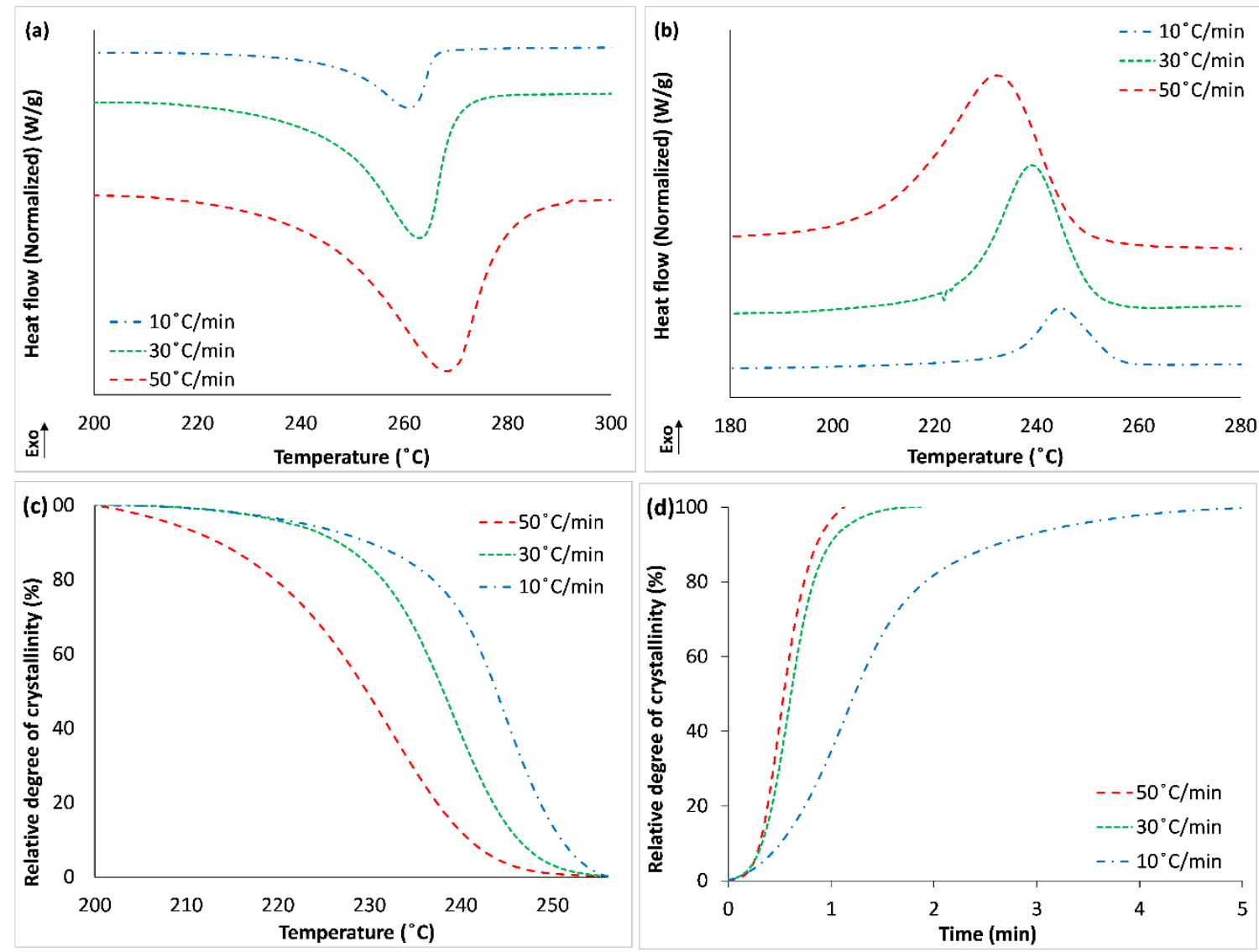

Fig. 5 DSC (a) $2^{\text {nd }}$ heating, and (b) cooling curves of the nanocomposites as a function of cooling rate. And relative degree of crystallinity as a function of (c) temperature, and (d) time for different cooling rates.

Table 2 shows the degree of crystallinity in the samples that have been cooled down at different rates. Results showed that higher cooling rates lead to lower degrees of crystallinity. In fact, as the speed of crystallization increases, there would be less time for polymer chains to rearrange, and for the crystals to grow that result into lower degrees of crystallinity in total. It is also noteworthy to mention that addition of nanofiller in the polymeric matrix has led to higher degrees crystallinity. However, the degrees of crystallinity slightly decreased in $6.0 \mathrm{wt}$. \% of nanotube content compared to the $3.0 \mathrm{wt}$. \% reinforced composites. In fact, it seems that incorporation of higher number of the tubes reduce the required space for the crystals to grow. Moreover, their rearrangement of polymer chains becomes more difficult among higher numbers of the tubes. Therefore, no further increase in the crystallization can be expected in higher contents of the tubes. Moreover, it is noteworthy to mention that the glass transition temperatures $\left(\mathrm{T}_{\mathrm{g}}\right)$ decreased to $47.8^{\circ} \mathrm{C}$ in the nanocomposites containing 6.0 wt. \% MWCNTs. 
Table 2. Nonisothermal crystallization parameters acquired from the DSC curves

\begin{tabular}{lcccc}
\hline $\begin{array}{c}\text { Nanocomposite } \\
\text { Specimen }\end{array}$ & $\begin{array}{c}\text { Cooling rate } \\
\left({ }^{\circ} \mathrm{C} / \mathrm{min}\right)\end{array}$ & $\begin{array}{c}\text { Crystallization } \\
\text { peak } \\
\text { temperature } \\
\left.\mathrm{Tc}^{\circ} \mathrm{C}\right)\end{array}$ & $\begin{array}{c}\text { Crystallization } \\
\text { onset } \\
\text { temperature } \\
\mathrm{T}_{\text {onset }}\left({ }^{\circ} \mathrm{C}\right)\end{array}$ & $\begin{array}{c}\text { Degree of } \\
\text { crystallinity } \\
\mathrm{X}_{\mathrm{C}}(\%)\end{array}$ \\
\hline PA 66 neat & 10 & 235.6 & 238.8 & 38.11 \\
\hline PA 6,6 + 3.0 wt. & 10 & 243.1 & 253.4 & 42.2 \\
\% MWCNT & 30 & 238,9 & 248.3 & 41.3 \\
\hline PA 6,6 + 6.0 wt. & 50 & 232,1 & 246.1 & 40.8 \\
\% MWCNT & 10 & 244.7 & 255.9 & 41.4 \\
& 30 & 239.2 & 250.6 & 41.0 \\
\hline
\end{tabular}

\subsection{Influence of injection molding parameters}

Finding the appropriate method and setting for melt compounding of the MWCNT filled composites led to the investigation of the influence of injection molding parameters on the properties of the manufactured nanocomposites. To perform these analyses, master-batches were diluted to $3.0 \mathrm{wt}$. \% of MWCNT in the PA 6,6 matrix. SEM investigations on the initially produced specimens containing $3.0 \mathrm{wt}$. \% of the nanofillers showed that in this content of the nanotubes, a fairly stable dispersion state can be achieved using the obtained parameters in the compounding section. Therefore, the mechanisms involved in the variation of the properties can be analyzed regardless of the influence of the existing or reformed agglomerations in the nanocomposites. Fig 6 shows the achieved dispersion state in the $3.0 \mathrm{wt}$ \% of MWCNT reinforced nanocomposites. Statistical studies showed 1-2 agglomerates with maximum diameter of $3 \mu \mathrm{m}$ exist in the areas of $500 \mu \mathrm{m}^{2}$.
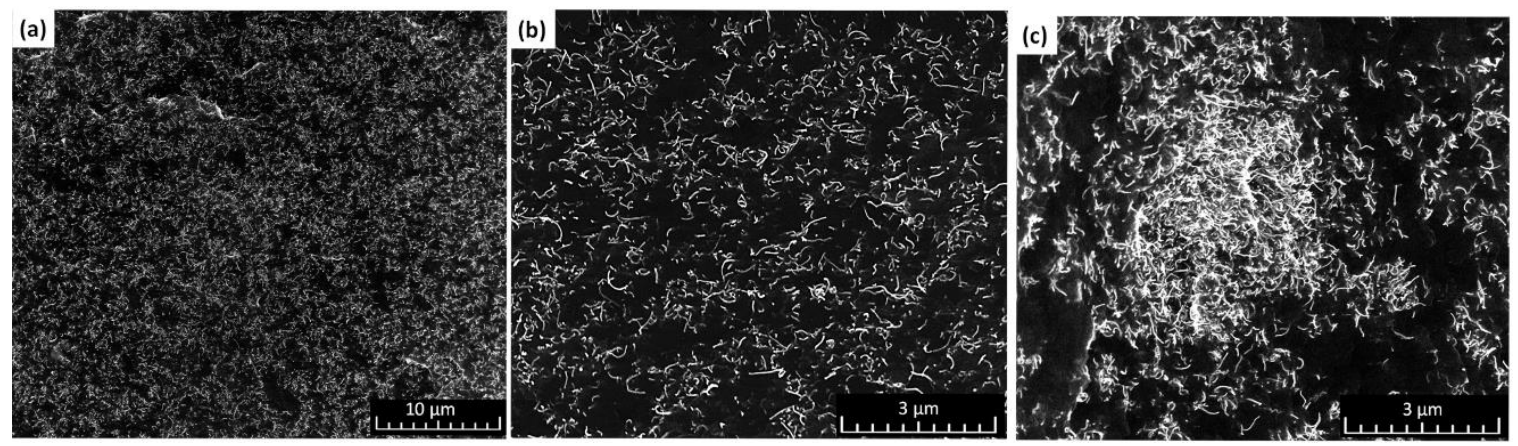

Fig. 6 (a) dispersion state of the nanocomposites containing 3.0 wt. \% MWCNTs. (b) the dispersed phase and (c) the agglomerate phase. 
Fig. 7 shows the influence of melt temperature on the elastic moduli and tensile strengths of the nanocomposites. A decline in the mechanical properties was observed by increasing the injection molding melting temperatures. This reduction in the mechanical properties after $20{ }^{\circ} \mathrm{C}$ increase in melt temperature is noteworthy. The electrical resistivity of the nanocomposites was also measured (Fig 7(c)). In contrast to the observed trend in the mechanical properties, increasing the injection molding melt temperature increased the conductivity of the nanocomposites significantly. An increase of $20{ }^{\circ} \mathrm{C}$ increased the conductivities the nanocomposites by more than 2 orders of magnitude.

In fact, higher melt temperatures in the injection molding process corresponds to higher temperature gradient between the melt and mold (i.e. higher cooling rate); thus, lower degrees of crystallinity is expected in the nanocomposites. It is well-known that carbon nanotubes act as nucleation sites for the crystallization of the polymer composites ${ }^{27}$. Therefore, in semi-crystalline polymers, a number of nanotubes are surrounded by the formed polymer crystals. While this phenomenon is advantageous to the mechanical properties, it acts against the electrical conductivity since the polymeric crystals are covering the tubes and retarding the contact between the tubes. The DSC experimental results that higher cooling rates result in less crystallinity in the nanocomposites is in accordance with the observed mechanical and electrical trends. In other words, while mechanical properties has improved at lower melt temperatures (lower temperature gradient), and electrical conductivity is higher at elevated melt temperatures (higher temperature gradient). 

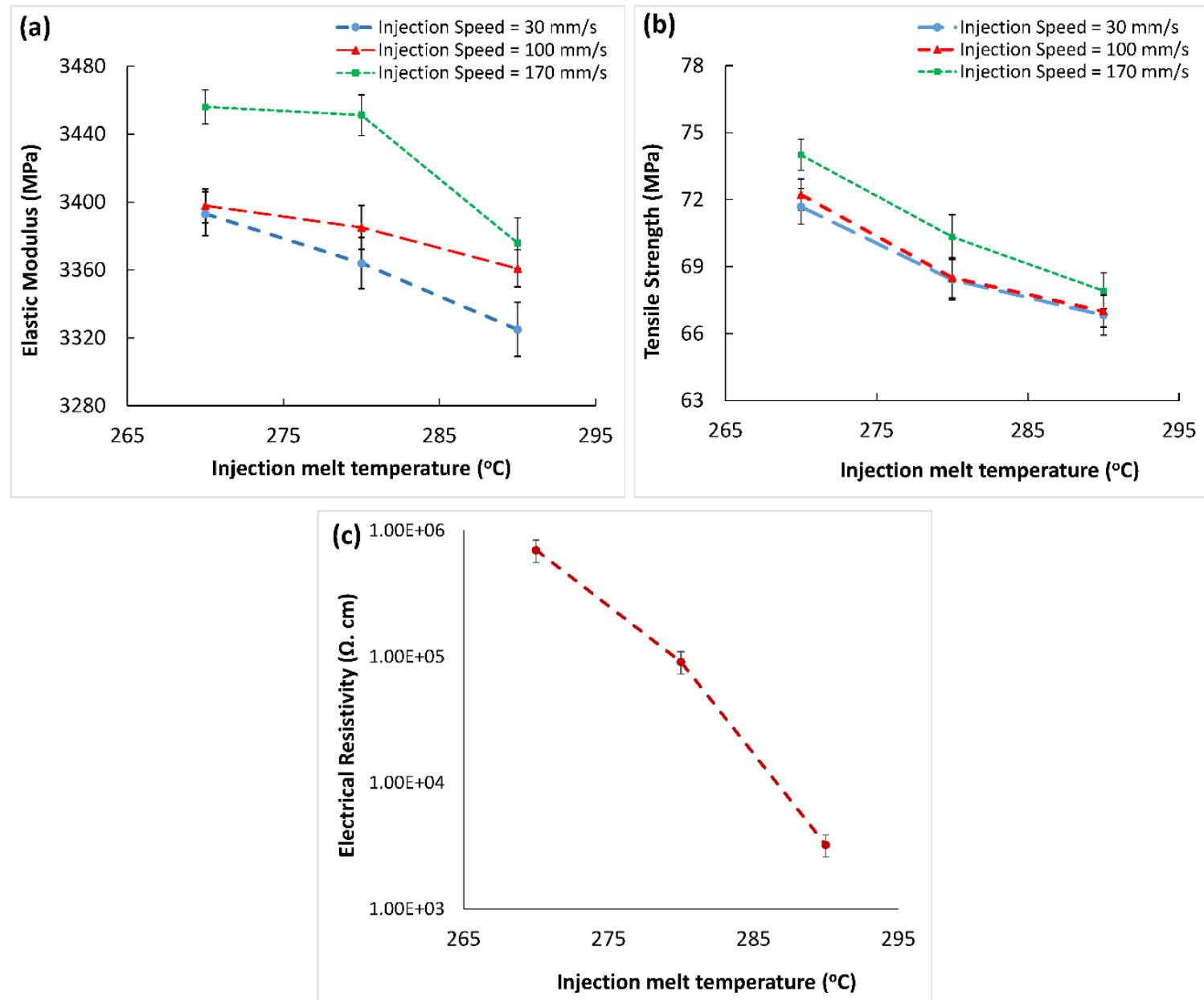

Fig. 7 Influence of injection melt temperature on the (a) Elastic modulus, (b) tensile strength, and (c) electrical resistivity of the nanocomposites.

Fig. 8 depicts the influence of injection speed on the mechanical and electrical properties of the nanocomposites. As it can be seen clearly from the diagrams, both elastic moduli and tensile strengths of the nanocomposites increased in higher injection speeds. In fact, carbon nanotubes because of their nanometer diameters follow the same pattern of the polymer molecules flow during the injection molding process. While filling of the mold, orientation effects arise through friction forces. The polymer molecules and nanotubes that are initially in a random state are stretched and orientated in the direction of flow. As the shear rate increases, the orientation of the polymer chains will become greater. Therefore, higher alignment is expected in the incorporated tubes. This higher shear rate along with the high viscosity of the polymer melt leads to additional shear forces on the melt flow. That is also the reason behind additional enhancement in the nanocomposites processed in lower melting temperatures.

However, despite higher alignment of the nanotubes and polymer chains in larger injection speeds, a counteracting parameter is invoked simultaneously. Raising injection speed increases the friction heat in system, which in turn decreases the viscosity. Therefore, 
nanotubes have more freedom to change their orientation during residing in the mold. Hence, it is expected that more polymer chains and nanotubes deviate from their delivered state to the mold at higher temperatures. This behavior also contributes to the enhancement of the mechanical properties in lower melt temperatures. On the other hand, it can also be deduced that a higher melt temperature eases the relaxation process and promotes the level of entanglements between the nanotubes during relaxation (see Fig. 4). In fact, this higher energy in less viscous atmosphere lets the nanotubes attract each other due to their high interfacial energy. The formed network of the nanotubes as an outcome of this enhanced interconnection leads to higher electrical conductivity. As mentioned before, a complex combination of several parameters including less viscosity, less temperature gradient, and higher levels of alignment lead to the improvement in the mechanical properties. Nevertheless, it seems that the summation of these counteracting parameters is toward the increase in the alignment and mechanical properties. Moreover, it seems that in spite of the supposedly better alignment as a function of injection speed, the accompanied elevated friction heat has rather promoted the wetting and the network of the carbon nanotubes resulting in the decreased resistivity of the composites.
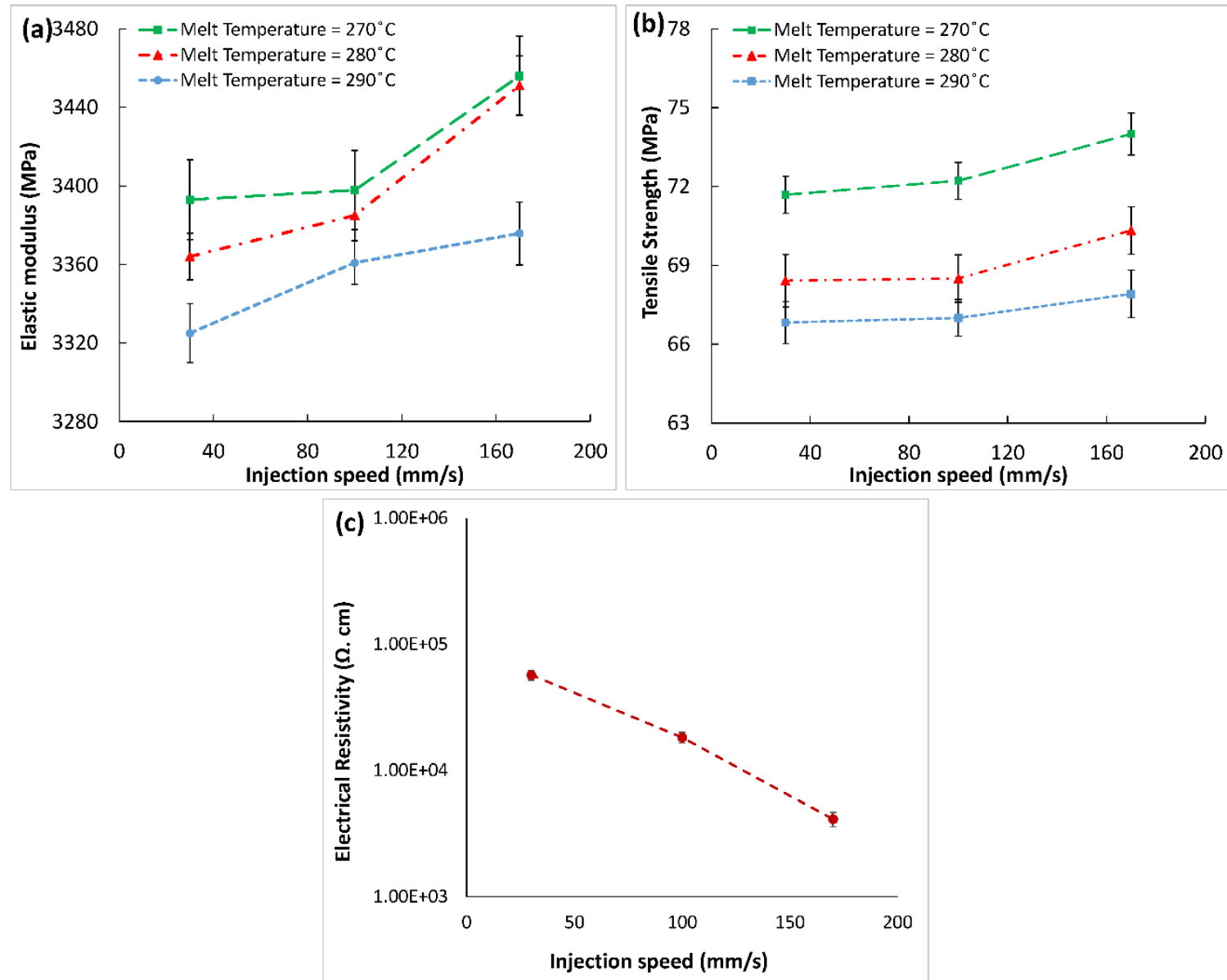

Fig. 8 Influence of injection speed on the (a) Elastic modulus, (b) tensile strength of 3.0 wt. \% MWCNT nanocomposites. 
The influence of holding pressure and mould temperature on the properties of the nanocomposites are illustrated in Fig. 9. The results did not show notable variation in the stiffness of the nanocomposites under influence of the two latter injection-molding parameters. However, increasing the holding pressure resulted into the enhancement of the tensile strengths. Moreover, the slope of the enhancement as a function of holding pressure decreased at elevated temperatures (Fig. 9 (a)). While the influence of holding pressure on the tensile strength of the nanocomposites is negligible at $\mathrm{T}_{\text {melt }}=290^{\circ} \mathrm{C}$, it becomes more noticeable at $\mathrm{T}_{\text {melt }}=270^{\circ} \mathrm{C}$. This behavior can be attributed to the rheological evolution of the nanocomposite melt at different temperatures. As the result of this lower melting temperature in the process, large portion of the part has already frozen. Moreover, polymer in the areas near the gate shows high melt viscosity (solid-state) and resistance to additional disturbance. Therefore, just the molten polymer near the gate would be affected and the middle area of the part will undergo additional compressive pressure, resulting in slight enhancement. Fig. 9 (b) shows the influence of the holding pressure on the electrical properties of the produced nanocomposites. Results showed that higher holding pressures lead to improvement in the electrical conductivities. In contrast to the influence of the variation in the melting temperatures, which led to the opposite trends in mechanical and electrical properties, increasing injection speed and holding pressure act in favor of both mentioned properties. It can be deduced that the increase in the holding pressure improves the network of the nanotubes. The parts produced using high packing pressure and held on for shorter packing time generally have a lower stress level than the parts made with a lower pressure. In other words, in parts produced under high packing pressure, the polymer chains and carbon nanotubes are in a more relaxed state. This additional relaxation means higher levels of entanglement and higher chances of contact between the carbon nanotubes. Therefore, an improved network of the tubes was achieved as the results of these contacts.

Furthermore, Figs 9 (c) and (d) illustrates the influence of mould temperature on the tensile strengths and electrical resistivity of the polymeric nanocomposites. The tensile strengths are increasing in higher mold temperatures, although this enhancement is moderate. This can also be justified by the discussion about the influence of cooling rates on the final properties. Increase in the mould temperature, which is equivalent to smaller temperature gradients, would lead to improved crystallinity and mechanical properties. However, it seems that regardless of the nanotube alignment, either additional contacts or less crystals growth is occurring where higher holding pressure is imposed on the system. It is also noteworthy that the electrical properties trend as a function of mould temperature is opposite to the observed trend in the mechanical properties. As discussed before, higher mould temperature or less temperature gradient causes higher relative levels of crystallinity. Therefore, crystals surrounding CNT weaken the contacts between the nanotubes in the amorphous phase of the polymer matrix; which in turn leads to less conductivity in the nanocomposites. 

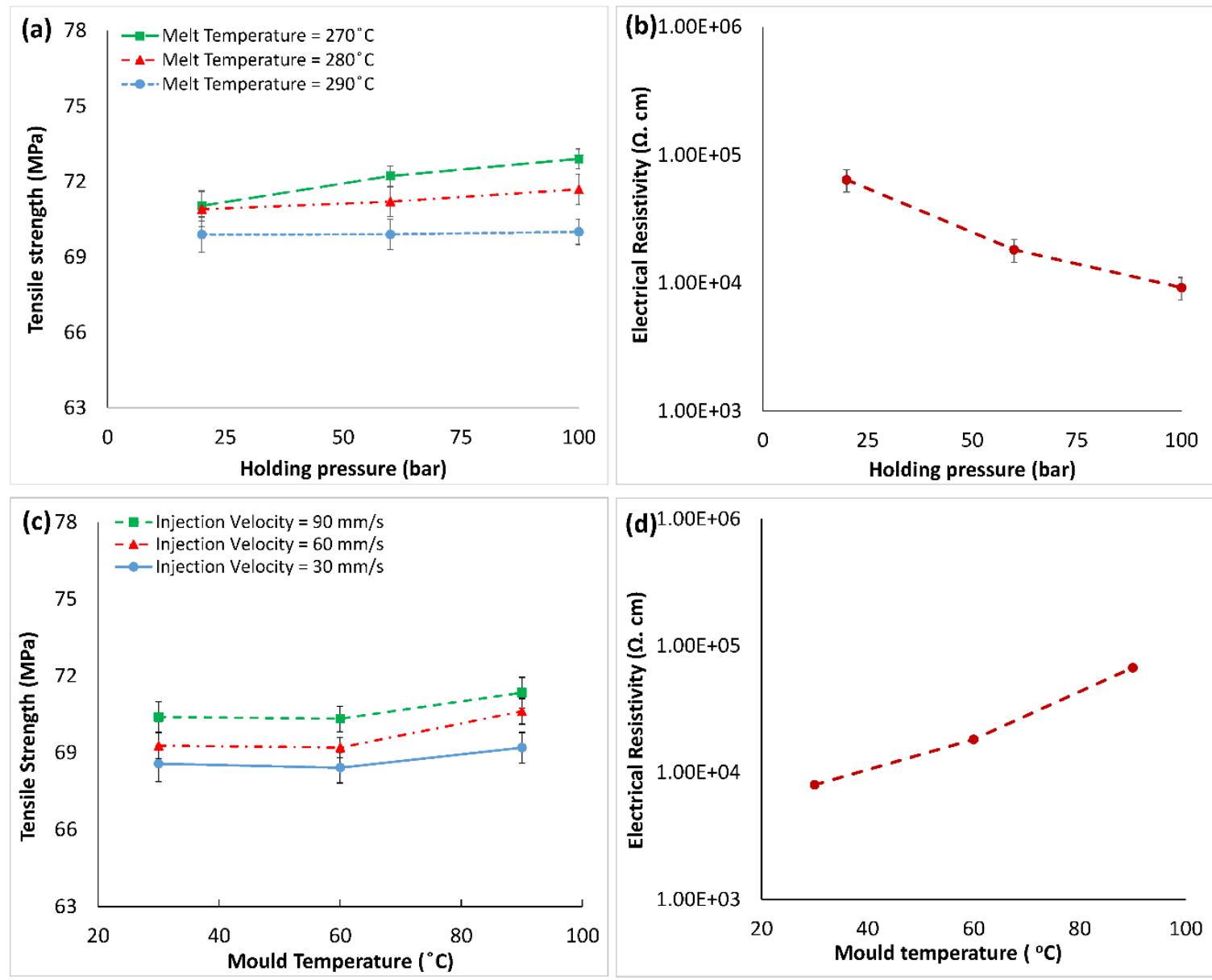

Fig. 9 Influence of (a), (b) holding pressure, and (b), (c) mould temperature on the tensile strength and electrical resistivity of the nanocomposite.

Fig. 10 shows TEM micrographs of the microstructure of the nanocomposites manufactured with the two different processing settings. The micrographs show that change in the processing parameters can lead to the different pattern of the nanotube arrangements in the composite. However, while mechanical properties are not significantly influenced by these changes, electrical properties are significantly influenced. The formed network of the nanotubes as the result of more entanglement and interaction between the tubes boosts the electrical conductivity. 

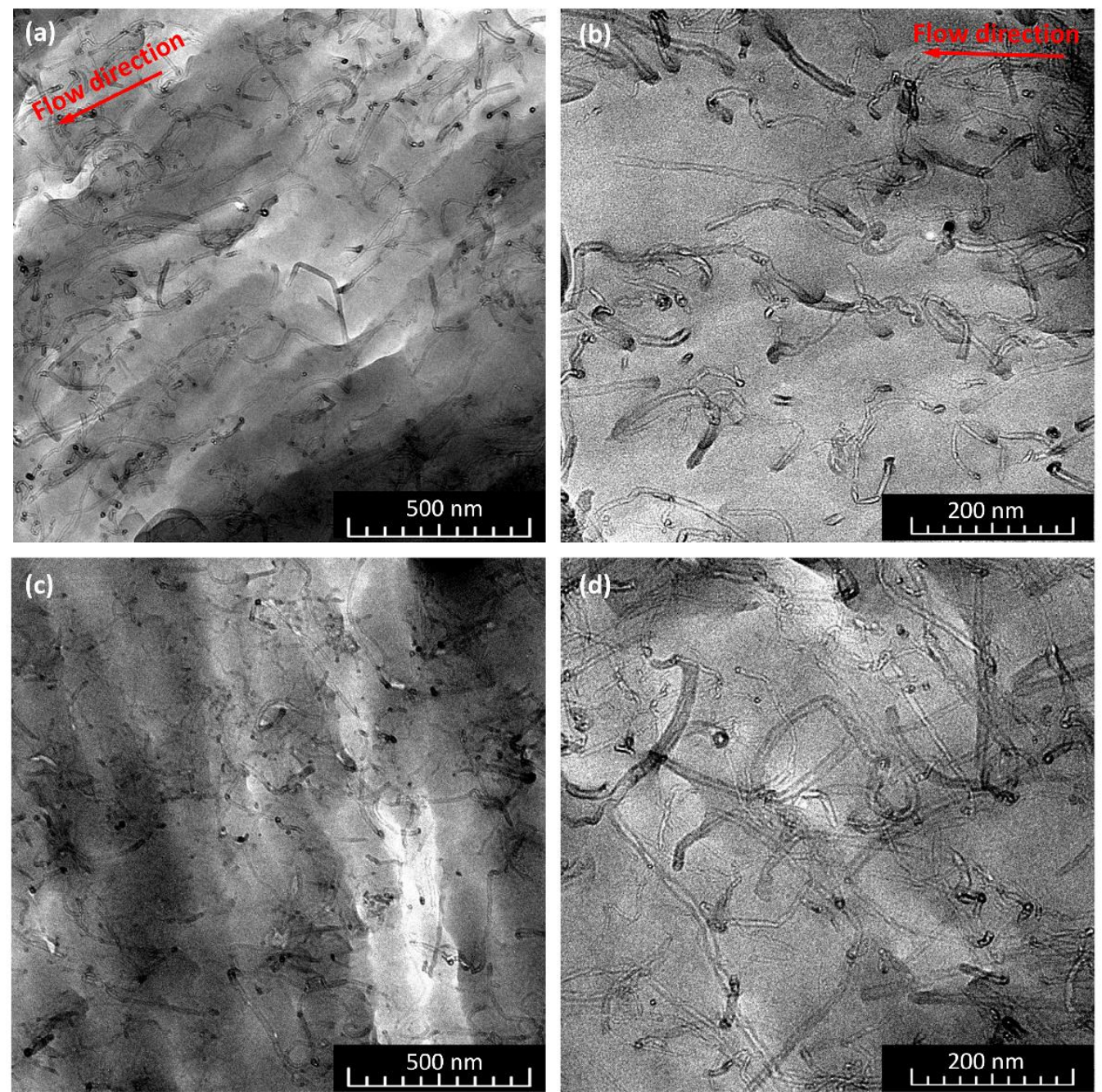

Fig. 10 Arrangement of nanotubes in the polymeric matrix under different processing settings: (a), (b) alignment along flow, and (c), (d) randomness.

In fact, in order to have enhancement in mechanical or electrical properties, different arrangements of the polymer chains and nanotubes are required (Fig. 11). In order to have a better mechanical properties in the PA 6,6 based nanocomposites, a good dispersion state is a crucial requirement. In addition, alignment of the tubes and higher levels of crystallinity promote the mechanical behavior. In contrast, a good dispersion state is not an indispensable requirement to the improvement of the electrical properties since the enhancement mechanisms are fundamentally different. Indeed, in addition to the network of well-dispersed CNTs, a network of CNT clusters and agglomerates would also create sound electrical behavior ${ }^{28}$. Moreover, alignment of the tubes is not advantageous to the electrical conductivities, since it decreases the probability of contact between neighboring nanotubes. For instance, as it can be seen from the Fig. 10(a) or (b) there is no connection between many tubes, while the formed microstructure with more randomness has created a vivid network leading to better electrical conductivity. Generally, as long as nanotubes 
either dispersed or in agglomerates are in functional contact or close enough to permit electrical tunneling, we can expect improved electrical properties.

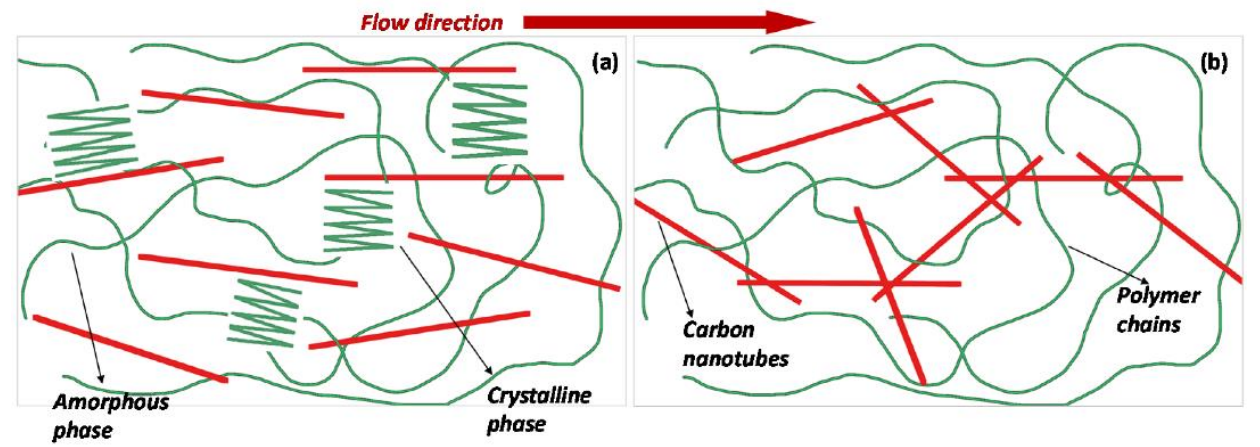

Fig. 11 The schematic of the microstructure leading to a better (a) mechanical and (b) electrical properties in the same content of carbon nanotubes in the matrix.

\subsection{Influence of content}

After determining the best processing parameters leading to enhanced mechanical or electrical performances, nanocomposites containing different contents of nanotubes were manufactured. Therefore, the influence of the content of the nanotubes on the behavior of the nanocomposites was studied. Nanocomposites containing 0.5, 1.0, 3.0, 5.0, and $6.0 \mathrm{wt}$. $\%$ of the nanotubes were prepared using the two sets of processing parameters targeting enhanced mechanical or electrical properties. Fig. 12 shows the performance of the nanocomposites as the function of nanotube content. Addition of nanotube content in the composite systems leads to increase in the stiffness values of the specimens produced using either of processing parameters. However, the enhancement rate is notably higher in the composites prepared using optimized setting for mechanical performance. This difference is more notable in the achieved tensile strengths. Using the setting targeting improved electrical properties led to similar tensile strengths in 1.0 and $6.0 \mathrm{wt}$ \% nanotube reinforced composites. Moreover, the deviation between the observed mechanical behaviors of the two series of the nanocomposites is increasing in higher filler contents. It should be noted that using either of the processing parameters lead to the enhancement of the elastic modulus or the electrical conductivity. In fact, multifunctional composites are being produced by incorporating carbon nanotubes in the polymeric matrix. However, in order to benefit from their potential efficiently, a prior property and microstructure should be chosen. Otherwise, using a mid-level injection speed and melting temperature results in increasing both properties. However, the enhancement level is between the two plotted curves in Fig. 12.

In order to investigate how the level of alignment and arrangement of the carbon nanotubes within the polymeric matrix influence the mechanical properties of the nanocomposites, a micromechanical model is employed. The equivalent continuum model 
based on the Eshelby-Mori-Tanaka approach has successfully been used for the prediction of elastic properties of the nanocomposites reinforced with the nanotubes ${ }^{29}$. Using this model enables us to attain the homogenized stiffness matrix of the nanocomposites ${ }^{30,31}$. The effective stiffness tensor $[C]$ of the two-phase nanocomposites can be estimated as ${ }^{32}$ :

$$
C=C_{m}+c_{r}\left\langle\left(C_{r}-C_{m}\right) A_{r}\right\rangle\left(c_{m} I+c_{r}\left\langle A_{r}\right\rangle\right)^{-1}
$$

where $C, C_{m}$, and $C_{r}$ are nanocomposite, matrix, and reinforcement stiffness tensors, respectively. In addition, $c_{m}$ and $c_{r}$ are matrix and reinforcement volume fractions, and $I$ is the identity tensor. $A_{r}$ represents the dilute mechanical strain concentration tensor:

$$
A_{r}=\left[I+S\left(C_{m}\right)^{-1}\left(C_{r}-C_{m}\right)\right]^{-1}
$$

where $S$ is Eshelby tensor that in case of cylindrical inclusions like the used carbon nanotubes, it can be estimated based on the Mura's theory ${ }^{33}$. Acquiring the stiffness matrix of the completely aligned homogenized representative volume elements enables us to attain the elastic properties of the nanocomposites with different arrangements and levels of alignment. Further details of the micromechanical modeling has been described in ${ }^{34}$.

Fig. 13 shows the stiffness prediction of the Mori-Tanaka micromechanical modeling as the function of nanotube content and level of randomness. In fact, in higher contents of the nanofillers, significant enhancement in mechanical properties is expected by alignment of the tubes. However, the experimental results did not show such behavior even using the setting optimized for mechanical performance. Moreover, the ratio of the experimental elastic moduli over the theoretical predictions is decreasing consistently, which indicates less control over orientation of the tubes is achievable in higher filler contents.
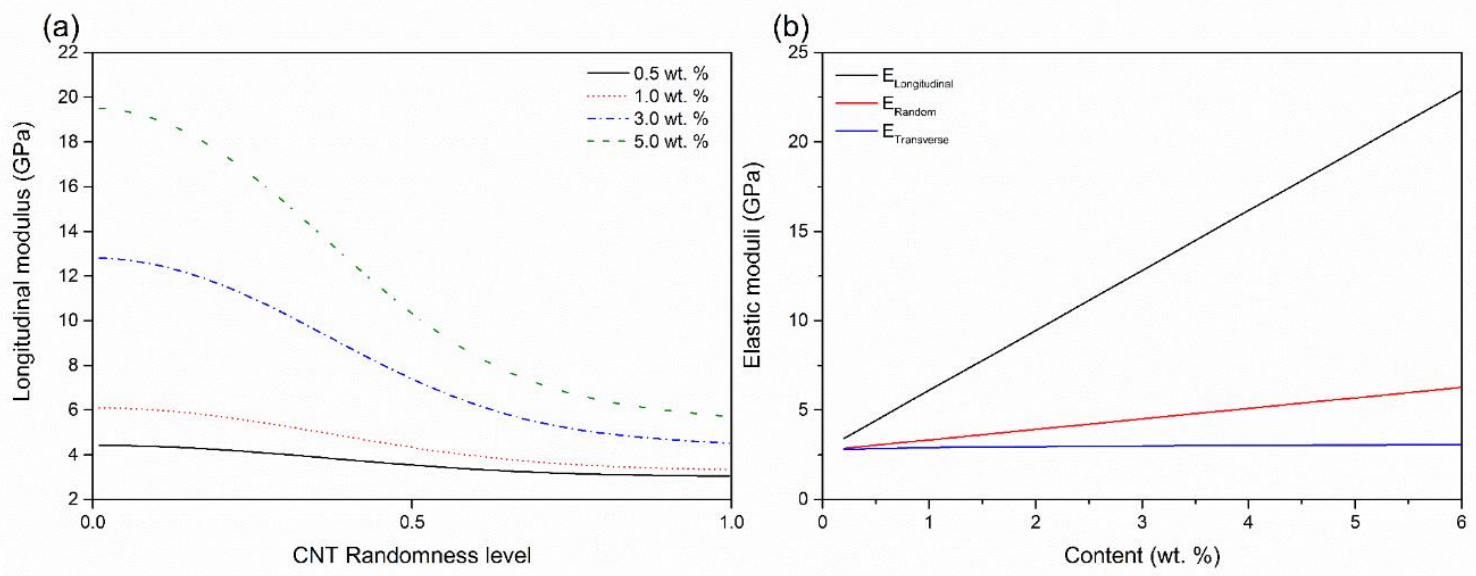

Fig. 12 Comparison between (a) elastic modulus values, (b) tensile strengths, and (c) electrical resistivities of the nanocomposites produced by the processing settings optimized for electrical and mechanical performances.

As it can be noticed, increasing the level of randomness and entanglement of the nanotubes reduces the elastic modulus drastically. In fact, long aspect ratio of the nanotubes 
(low bending stiffness) along with their high interfacial energy makes controlling their alignment and orientation a challenging task. In order to benefit from the inclusion of the stiff nanotubes in the polymeric matrix, a high level of nanotube alignment is required. However, incorporating more nanotubes results into the described solid-state melt that makes this alignment very difficult. This phenomenon might be one of the main reasons that theoretical predictions usually do not comply with experimental values in the realm of the nanocomposites reinforced with carbon nanotubes. In fact, the presence of the agglomerates is usually considered as the underlying reason behind the deviation of the theoretical predictions from the experimental results. However, our SEM investigations did not reveal significant presence of the agglomerates in the nanocomposites. Therefore, one might deduce that in higher concentration of the nanotubes within the polymeric matrix, aligning the nanofillers would be increasingly challenging. Therefore, it should be considered as the dominant parameter in the contrast of experimental and theoretical results. Although, the achieved limited control over morphology still affects the properties drastically. In fact, the notable variation in the electrical properties of the nanocomposites produced by the two series of parameters is the direct result of this change in the structure. Moreover, processing of the nanocomposites by the optimized setting targeting improved electrical behavior shifted the electrical percolation threshold to lower contents of the tubes. In higher contents of the nanotubes, a change in the number of contacts between the fillers can define if the nanocomposites are conductive or not. Therefore, a significant difference up to three orders of magnitude can be noticed in the nanocomposites containing 6.0 wt. \% MWCNTs. 

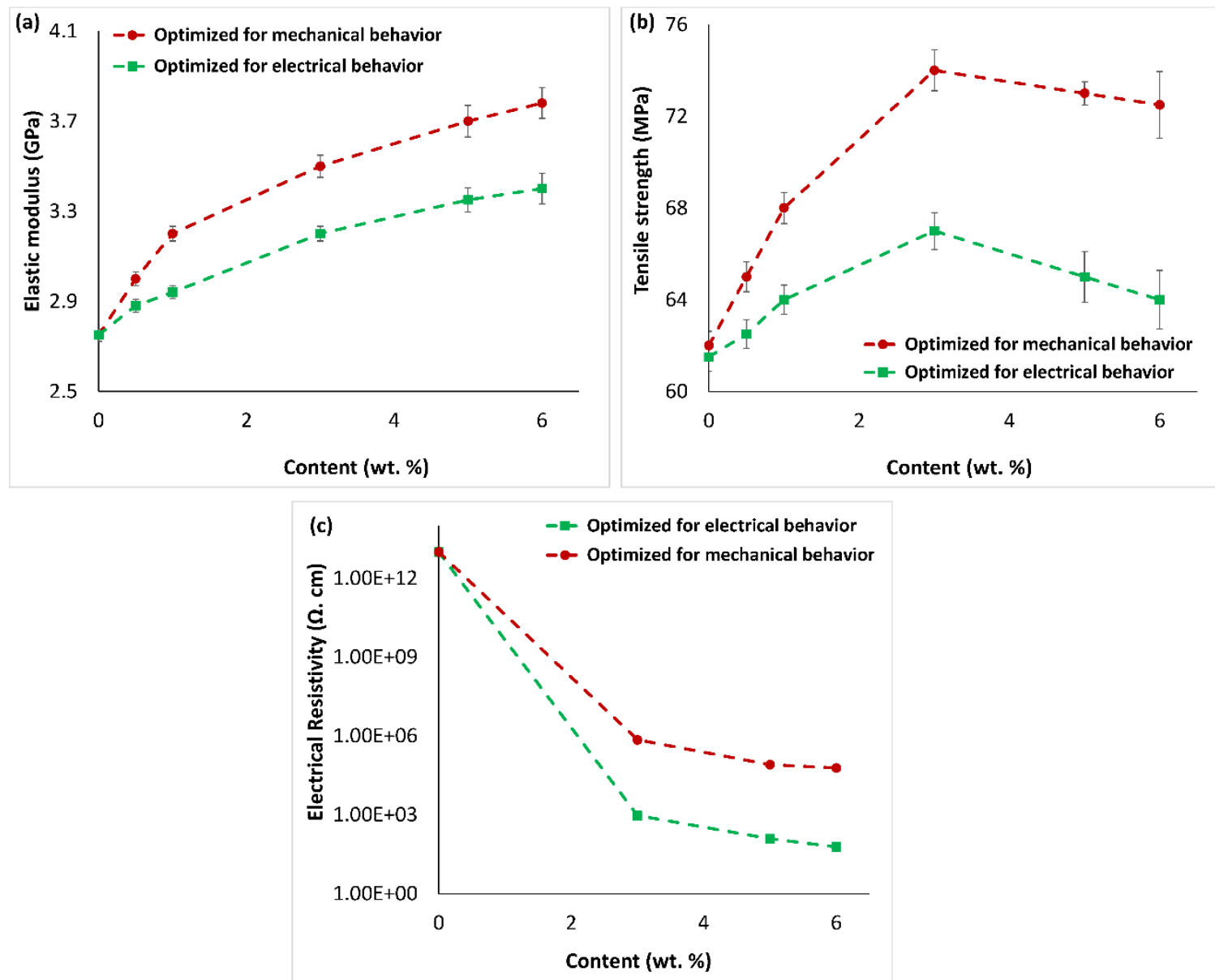

Fig. 13 Influence of nanotube (a) randomness and (b) content on the elastic modulus of the nanocomposites.

\section{Conclusions}

PA 6,6 based nanocomposites reinforced with different contents of multi-walled carbon nanotubes were prepared. The influence of the processing variables on the mechanical and electrical behavior was studied. The correlation between the observed trends with the microstructure of the nanocomposites was also investigated. Investigation of the influence of the dilution method on the properties revealed its crucial impact on mechanical properties due to its determinant role in defining the dispersion states. However, the electrical properties were less sensitive to the dilution method. The influence of the injection molding parameters on the structure and properties of the nanocomposites was also investigated. Experimental results showed that variations in melt and mould temperature result in the opposite mechanical and electrical enhancement trends. However, increase in the injection molding speed or holding pressure increased both mechanical and 
electrical properties. Probing into the underlying mechanisms of the observed trends suggested that the performance of the composites depends on several parameters, which sometimes are counteracting. Parameters such as dispersion state, alignment of the polymer chains and tubes, viscosity, relaxation behavior, and crystallization determine the behavior of the nanocomposites. Enhancement in electrical and mechanical properties requires completely different processing parameters and microstructures within the products. Moreover, studying the influence of content on the properties showed that less control over morphology of the nanocomposites is achievable in higher nanotube contents. However, this limited amount control can define the properties effectively. In fact, the applied setting defined the existence or absence of a nanotube network in the structure of the composites. The provided comprehensive picture of the properties as a function of the different complex parameters enables tailoring the nanocomposites to acquire the desired functions in the industrial applications.

\section{Acknowledgements}

Authors would like to thank GN Hearing A/S, Oticon A/S, and Widex A/S for their support in this project.

\section{References}

1. $\quad$ Iijima S. Helical microtubules of graphitic carbon. Nature 1991; 354: 56-58.

2. Thostenson E, Li C, Chou T. Nanocomposites in context. Compos Sci Technol 2005; 65: 491-516.

3. Ayatollahi MR, Doagou-Rad S, Shadlou S. Nano-/Microscale Investigation of Tribological and Mechanical Properties of Epoxy/MWNT Nanocomposites. Macromol Mater Eng 2012; 297: 689-701.

4. Mayoral B, Garrett G, McNally T. Influence of Screw Profile Employed During Melt Mixing on the Micro-scale Dispersion of MWCNTs in Poly(propylene). Macromol Mater Eng 2014; 299: 748-756.

5. Mahmoodi M, Arjmand M, Sundararaj U, et al. The electrical conductivity and electromagnetic interference shielding of injection molded multi-walled carbon nanotube/polystyrene composites. Carbon N Y 2012; 50: 1455-1464.

6. Villmow T, Pegel S, Pötschke P, et al. Influence of injection molding parameters on the electrical resistivity of polycarbonate filled with multi-walled carbon nanotubes. Compos Sci Technol 2008; 68: 777-789.

7. Wegrzyn M, Juan S, Benedito A, et al. The influence of injection molding parameters on electrical properties of PC/ABS-MWCNT nanocomposites. $J$ Appl Polym Sci 2013; 130: 2152-2158.

8. Ch. Hopmann, J. Fragner SH. Development of electrically conductive plastic compounds based on filler combinations. J Plast Technol 2014; 10: 49-67.

9. Doagou-Rad S, Islam A, Jensen JS. Influence of Processing Conditions on the Mechanical Behavior of MWCNT Reinforced Thermoplastic Nanocomposites. Procedia CIRP 2017; 66: 131-136. 
10. Choong GYH, Lew CY, De Focatiis DSA. Role of processing history on the mechanical and electrical behavior of melt-compounded polycarbonatemultiwalled carbon nanotube nanocomposites. J Appl Polym Sci 2015; 132: 42277.

11. Kingston C, Zepp R, Andrady A, et al. Release characteristics of selected carbon nanotube polymer composites. Carbon N Y 2014; 68: 33-57.

12. Krause B, Pötschke P, Häußler L. Influence of small scale melt mixing conditions on electrical resistivity of carbon nanotube-polyamide composites. Compos Sci Technol 2009; 69: 1505-1515.

13. Rahmat M, Hubert P. Carbon nanotube-polymer interactions in nanocomposites: A review. Compos Sci Technol 2011; 72: 72-84.

14. Rios PF, Ophir A, Kenig S, et al. Impact of injection-molding processing parameters on the electrical, mechanical, and thermal properties of thermoplastic/carbon nanotube nanocomposites. J Appl Polym Sci 2011; 120: 7078.

15. Villmow T, Pegel S, Pötschke P, et al. Influence of injection molding parameters on the electrical resistivity of polycarbonate filled with multi-walled carbon nanotubes. Compos Sci Technol 2008; 68: 777-789.

16. Tiusanen J, Vlasveld D, Vuorinen J. Review on the effects of injection moulding parameters on the electrical resistivity of carbon nanotube filled polymer parts. Compos Sci Technol 2012; 72: 1741-1752.

17. Lellinger $\mathrm{D}, \mathrm{Xu} \mathrm{D}$, Ohneiser A, et al. Influence of the injection moulding conditions on the in-line measured electrical conductivity of polymer-carbon nanotube composites. Phys status solidi 2008; 245: 2268-2271.

18. Chandra A, Kramschuster AJ, Hu X, et al. Effect of injection molding parameters on the electrical conductivity of polycarbonate / carbon nanotube nanocomposites. Mech Eng 2007; 4: 2184-2188.

19. Stan F, Sandu LI, Fetecau C. Effect of processing parameters and strain rate on mechanical properties of carbon nanotube-filled polypropylene nanocomposites. Compos Part B Eng 2014; 59: 109-122.

20. Islam A, Hansen HN, Tang PT. Direct electroplating of plastic for advanced electrical applications. CIRP Ann 2017; 66: 209-212.

21. Brandrup J, Immergut EH, Grulke EA, et al. Polymer handbook. 2nd ed. New York: John Wiley \& Sons, Inc., 1989.

22. Hamaker HC. The London - van der Waals attraction between spherical particles. Physica 1937; 4: 1058-1072.

23. Rumpf H. The strength of granules and agglomerates. In: Knepper W (ed) Agglomeration. New York: Interscience Publishers, 1962, p. 379.

24. Wang Z, Yang X, Wei J, et al. Morphological, electrical, thermal and mechanical properties of phtalocyanine/multi-wall carbon nanotubes nanocomposites prepared by masterbatch dilution. J Polym Res 2012; 19: 19:9969.

25. Pötschke P, Fornes TD, Paul DR. Rheological behavior of multiwalled carbon nanotube/polycarbonate composites. Polymer (Guildf) 2002; 43: 3247-3255.

26. Rhoades AM, Williams JL, Androsch R. Crystallization kinetics of polyamide 66 at processing-relevant cooling conditions and high supercooling. Thermochim Acta 2015; 603: 103-109.

27. Li L, Li CY, Ni C, et al. Structure and crystallization behavior of Nylon 66/multi- 
walled carbon nanotube nanocomposites at low carbon nanotube contents. Polymer (Guildf) 2007; 48: 3452-3460.

28. Alig I, Pötschke P, Lellinger D, et al. Establishment, morphology and properties of carbon nanotube networks in polymer melts. Polymer (Guildf) 2012; 53: 4-28.

29. Alian AR, Kundalwal SI, Meguid SA. Multiscale modeling of carbon nanotube epoxy composites. Polymer (Guildf) 2015; 70: 149-160.

30. Mori T, Tanaka K. Average stress in matrix and average elastic energy of materials with misfitting inclusions. Acta Metall 1973; 21: 571-574.

31. Eshelby JD. The determination of the elastic field of an ellipsoidal inclusion, and related problems. In: Proceedings of the Royal Society of London A:

Mathematical, Physical and Engineering Sciences. The Royal Society, 1957, pp. 376-396.

32. Benveniste Y. A new approach to the application of Mori-Tanaka's theory in composite materials. Mech Mater 1987; 6: 147-157.

33. Mura T. Micromechanics of defects in solids. Springer Science \& Business Media, 2013.

34. Doagou Rad S, Jensen JS, Islam A. Multi-Scale Modeling of the Structural and Vibrational Behavior of Carbon Nanotube Reinforced Polymeric Nanocomposite Plates. Proceedings of the sixth ECCOMAS Thematic Conference on the Mechanical Response of Composites, Joris J.C. Remmers and Albert Turon (Eds). Eindhoven University of Technology, 2017, pp. 94-106. 